\title{
A DESIGN OF TRIPLE-BAND SLOT LOADED CIRCULAR MICROSTRIP ANTENNA FOR C- AND X- BAND APPLICATIONS
}

\author{
Boya Satyanarayana ${ }^{1}$, S. N. Mulgi² \\ ${ }^{I}$ Research Scholar, Department of P. G. Studies and Research in Applied Electronics, Gulbarga University, Gulbarga, \\ Karnataka, India \\ ${ }^{2}$ Professor, Department of P. G. Studies and Research in Applied Electronics, Gulbarga University, \\ Gulbarga, Karnataka, India
}

\begin{abstract}
The design and development of a triple-band slot loaded circular microstrip antenna is demonstrated in this paper for the applications of $C(4.66-8 \mathrm{GHz})$ and $X(8.91-9.93 \mathrm{GHz})$ bands. The proposed antenna design consists of a pair of connected square slots which are centrally inserted on the circular radiating element. The antenna resonates at three frequencies of 4.76, 7.45 and $9.27 \mathrm{GHz}$ with impedance bandwidths of 3.98\% (4.67-4.86 GHz), $17.40 \%(6.82-8.12 \mathrm{GHZ})$ and $14.48 \%$ (8.58-9.92 GHz) respectively. The antenna is excited through a simple 50- $\Omega$ microstripline feed. The proposed antenna may suitable for uplink and downlink of C-band satellite communication and of $X$ band radar applications. The simulation results are obtained by utilizing 3-D full-wave finite element method based high frequency structural simulator (HFSS) for comparison of experimental results. Acceptable agreement is observed between the both simulation and experimental results.
\end{abstract}

Keywords: Connected square slots, circular microstrip antenna, triple-band, $C$ - and X-band. $* * *$

\section{INTRODUCTION}

Nowadays most of the modern wireless communication systems especially in the field of satellites and modern radar systems, radio frequency identification (RFID), personal communication services (PCS) etc. finds the microstrip antennas (MSAs) are most useful and successful element for transmitting and receiving the electromagnetic (EM) signals, due to their special advantages such as less expensive, compact physical profile, easy to manufacture and easy to integrate with other microwave systems [1-2]. Also the recent technologies are more expecting the improved parameters of MSAs and antenna should operate for more than one frequency bands. Hence, in the recent consecutive decades there is lot of innovative techniques to improve the performance of the MSAs and multi-frequency operations were reported by many antenna designers. Since then a great amount of research activities are taking place throughout the world for both academic and industrial societies. The antenna parameters such as return loss, wider impedance bandwidth, efficiency, radiation characteristics and gain etc. have been investigated and reported in numerous technical papers by several techniques including the cutting slots in both radiating patch or ground plane [3-6], use of shorting pins and shoring walls [7-9], gap coupled [10], aperture coupled [11-12], proximity coupled [13-14] etc.

Also for several wireless communication applications the requirement of dual-frequency and triple-frequency operation with wider impedance bandwidth is more useful. A single element MSA for dual-frequency operation using shorting pins was proposed in [15]. A rectangular notch square patch for dual-frequency operation by using coaxial feed is proposed in [16]. The compact multiband antenna configuration for GPS, DCS and WLAN applications is reported in [17] using FR4 substrate fed by single feed. But in this paper a circular microstrip antenna with connected slots loaded on the patch is demonstrated for the triple band operation which is found to be rare in the literature.

\section{ANTENNA DESIGN CONSIDERATIONS}

The conventional circular microstrip antenna (CCMSA) and connected two square slot loaded circular microstrip antenna (CTSCMSA) are manufactured using a commercially available low cost glass epoxy substrate material of thickness $\mathrm{h}=0.16 \mathrm{~cm}$ with relative permittivity $\varepsilon_{\mathrm{r}}=4.2$ and dielectric loss tangent $\tan \delta=0.02$. The structures of these antennas are drawn by using AutoCAD software.

Figure 1 shows the top view geometry of CCMSA. The CCMSA geometry consisting a circular radiating element of radius ' $a$ '. This antenna is powered through a simple $50 \Omega$ microstripline feed of dimensions length $\mathrm{L}_{\mathrm{f}}$ and width $\mathrm{W}_{\mathrm{f}}$ is used for impedance matching. Also the quarter wavelength transformer having length $\mathrm{L}_{t}$ and width $\mathrm{W}_{\mathrm{t}}$ is fixed to match the impedance between the circular patch and the microstripline feed. A $50 \quad \Omega$ semi miniature-A (SMA) 
connector is connected at the end point of the microstripline for feeding the microwave power.

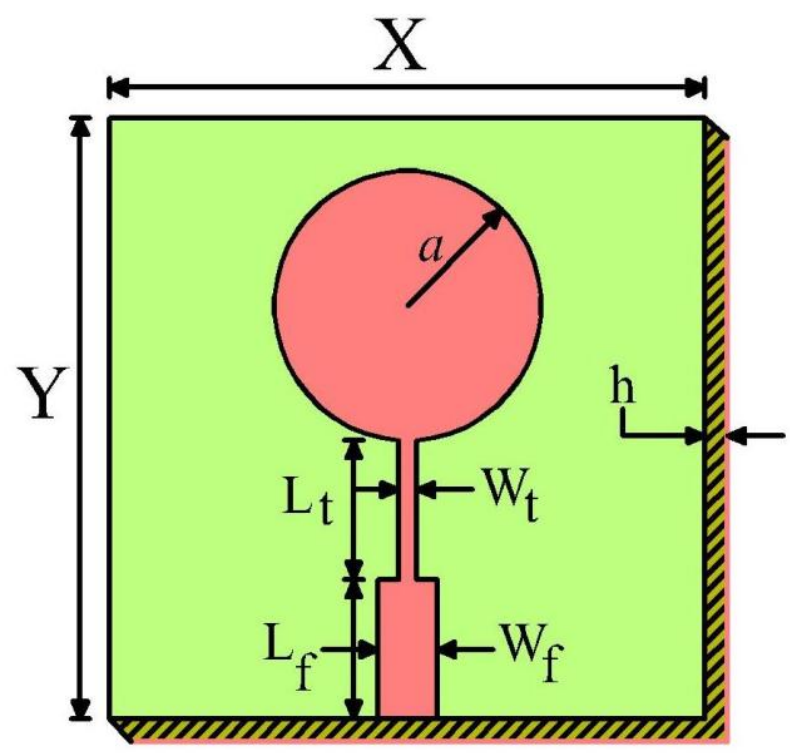

Fig -1: Top view geometry of CCMSA

The CCMSA has been designed for $3 \mathrm{GHz}$. The physical radius ' $a$ ' of the circular radiating patch is approximately determined from equation [18],

$$
a=\frac{F}{\left\{1+\frac{2 h}{\pi \varepsilon_{r} F}\left[\ln \left(\frac{\pi F}{2 h}\right)+1.7726\right]\right\}^{\frac{1}{2}}}
$$

Where,

$$
F=\frac{8.791 \times 10^{9}}{f_{r} \sqrt{\varepsilon_{r}}}
$$

Along the circumference of the conventional circular radiating patch the fringing fields are appears, thus by replacing the physical radius ' $a$ ' by effective radius ' $a$ ' which is given by [18],

$$
a_{e}=a\left\{1+\frac{2 h}{\pi a \varepsilon_{r}}\left[\ln \left(\frac{\pi a}{2 h}\right)+1.7726\right]\right\}^{\frac{1}{2}}
$$

The top view geometry of CTSCMSA is as shown in Fig -2. This antenna structure is adopt from CCMSA and consists of two equal dimensions of square slots which are connected together and inserted centrally on the circular radiating patch. The one offset square slot is exactly placed at the center from left side of the circular radiating patch. The length and width of the offset square slot $\left(S 1_{\mathrm{W}}\right.$ and $\left.S 1_{\mathrm{L}}\right)$ are equal to $\lambda_{0} / 14.28$. The other offset square slot is placed exactly at centered from right side of the patch. The dimensions of left off square slot $\left(\mathrm{S} 2_{\mathrm{W}}\right.$ and $\left.\mathrm{S} 2_{\mathrm{L}}\right)$ are same as that of the right offset square slot and are connected together. The total length $l$ of the two square slots is $\lambda_{0} / 7.14$ and distance ' $d$ ' between the connected offset square slots is $\lambda_{0} / 28.56$ which is also shown in Fig -2 . The parameters of the designed antennas are given in Table-I.

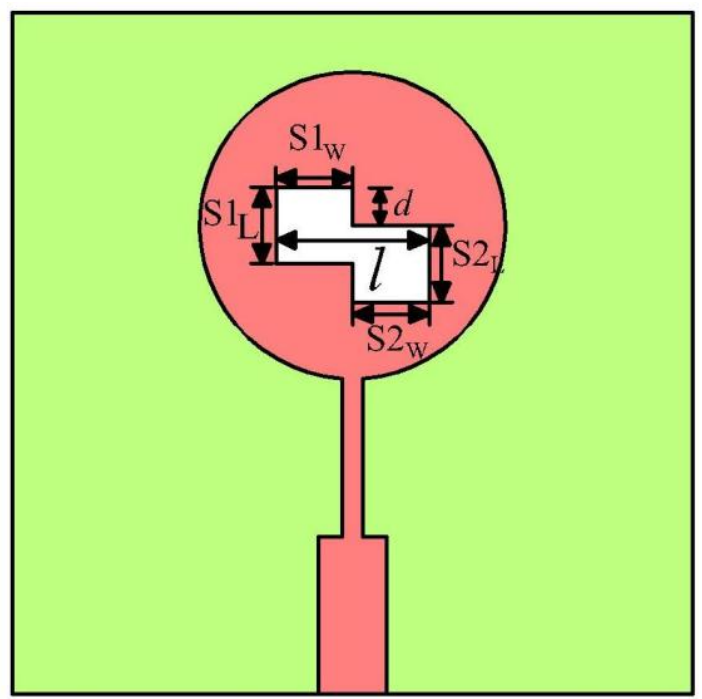

Fig -2: Top view geometry of CTSCMSA

Table -I: The designed parameters of proposed antennas.

\begin{tabular}{|c|c|}
\hline $\begin{array}{c}\text { Antenna geometry } \\
\text { parameters }\end{array}$ & $\begin{array}{c}\text { Parameter dimensions } \\
\text { in cm }\end{array}$ \\
\hline $\mathrm{a}$ & 1.361 \\
\hline $\mathrm{L}_{\mathrm{f}}$ & 1.23 \\
\hline $\mathrm{W}_{\mathrm{f}}$ & 0.317 \\
\hline $\mathrm{L}_{\mathrm{t}}$ & 1.23 \\
\hline $\mathrm{W}_{\mathrm{t}}$ & 0.066 \\
\hline $\mathrm{S} 1_{\mathrm{W}}$ and $\mathrm{S} 1_{\mathrm{L}}$ & 0.7 \\
\hline $\mathrm{S} 2_{\mathrm{W}}$ and $\mathrm{S} 2_{\mathrm{L}}$ & 0.7 \\
\hline$d$ & 0.35 \\
\hline
\end{tabular}

\section{EXPERIMENTAL RESULTS \& DISCUSSIONS}

The impedance bandwidths over return loss less than -10dB for the proposed antennas are measured. Figure 3 shows the variation of return loss versus frequency of CCMSA. It is keen observed from this figure that, the CCMSA resonates at $3 \mathrm{GHz}$ which is highly accurate to the design frequency of $3 \mathrm{GHz}$. The experimental impedance bandwidth is defined as

$$
\text { Impedance Bandwidth }(\%)=\left[\frac{f_{H}-f_{L}}{f_{C}}\right] \times 100 \%
$$


Where, $f_{H}$ is the higher cutoff frequency and $f_{L}$ is the lower cutoff frequency and $f_{C}$ is central frequency of the bands. The impedance bandwidth BW of CCMSA is determined when its return loss reaches the $10-\mathrm{dB}$ found to be about $2.93 \%$. The HFSS simulation result of CCMSA is also shown in Fig-3. The reasonable agreement is obtained between simulation and experimental results.

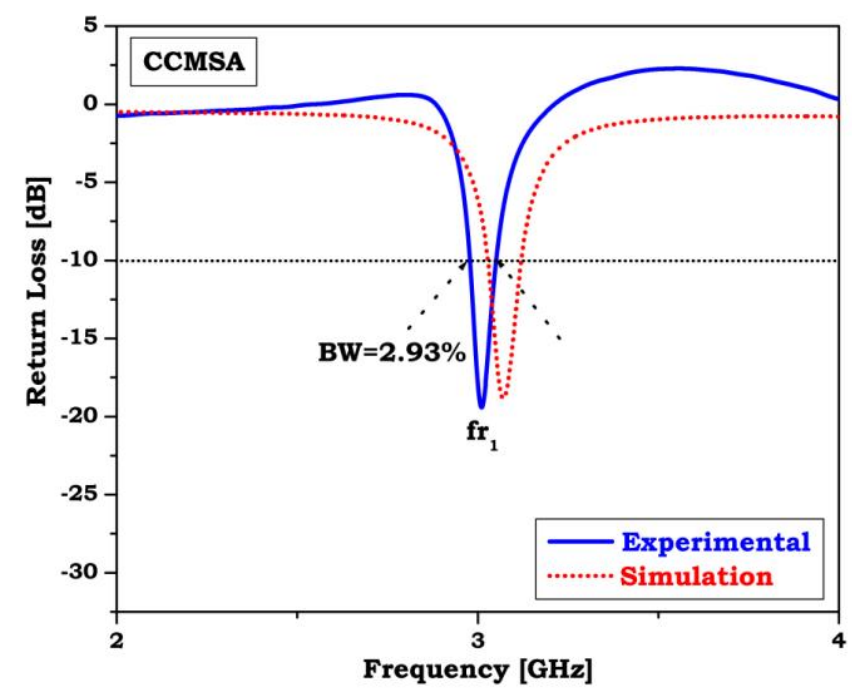

Fig -3: Variation of return loss versus frequency of CCMSA.

The variation of return loss versus frequency of CTSCMSA is as shown in Fig. 4. From this figure it is evident that, the antenna resonates for three resonant frequency modes at $f_{r 1}, f_{r 2}$, and $\mathrm{f}_{\mathrm{r} 3}$, having an impedance bandwidth of $\mathrm{BW}_{1}=3.56 \%$ (4.69 $\mathrm{GHz}-4.86 \mathrm{GHz}), \mathrm{BW}_{2}=16.84 \%(6.85 \mathrm{GHz}-8.11 \mathrm{GHz})$ and $\mathrm{BW}_{3}=14.5 \%(8.60 \mathrm{GHz}-9.91 \mathrm{GHz})$ respectively. It is also clear that, each operating bands are quit large compared to the impedance bandwidth of CCMSA and triple bands are possible by constructing CTSCMSA from CCMSA. For the first and second operating bands, the obtained impedance bandwidth is $\mathrm{BW}_{1}=3.56 \%$ and $\mathrm{BW}_{2}=16.84 \%$ which effectively covers the requirement of the uplink and downlink of C-band satellite communication application. For the third operating band, the impedance bandwidth $\mathrm{BW}_{3}=14.5 \%$ is obtained, this range is useful for covering the $\mathrm{X}$-band uplink satellite communication. The simulated result is in good agreement with the measured result.

The typical radiation patterns are measure at 3, 7.48 and 9.25 $\mathrm{GHz}$ of the CCMSA and CTSCMSA which are presented in Fig-5. The proposed antenna gives good broadside radiation characteristics at three operating bands.

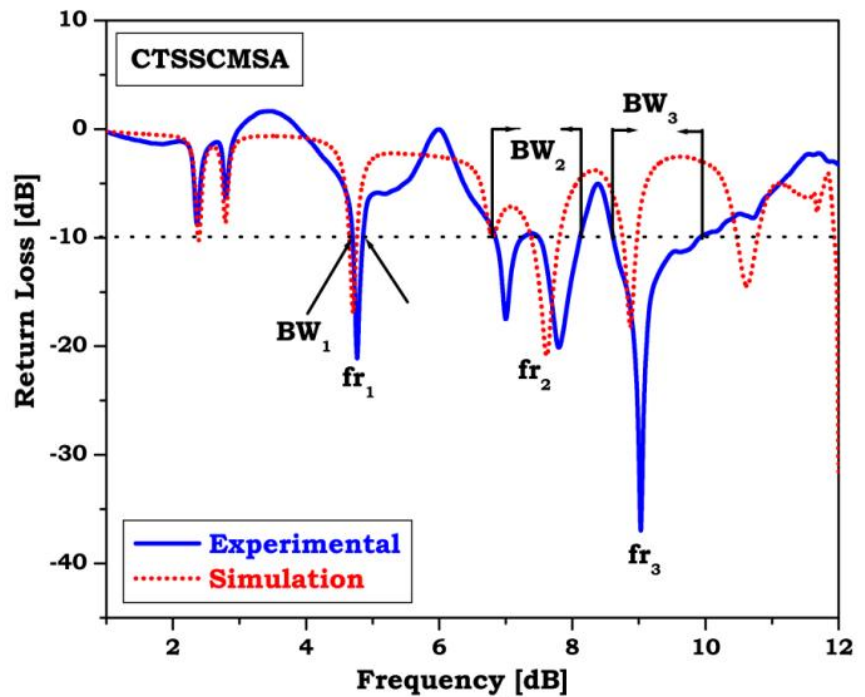

Fig -4: Variation of return loss versus frequency of CCMSA.

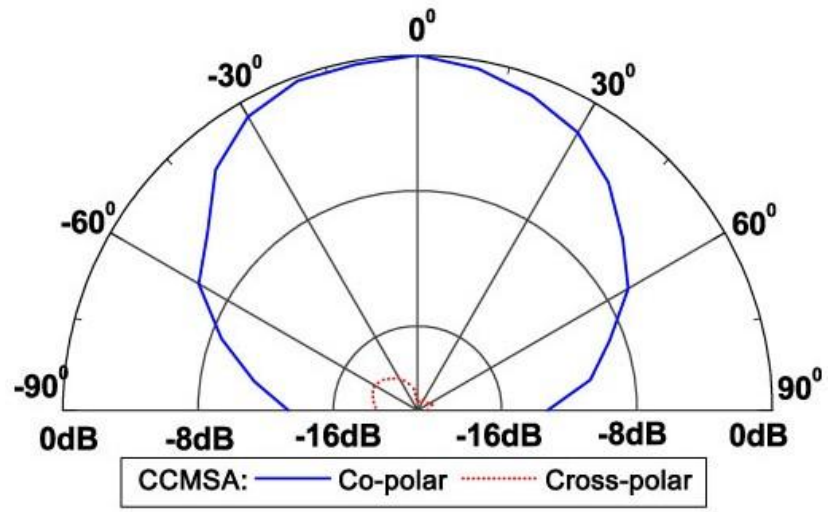

(a)

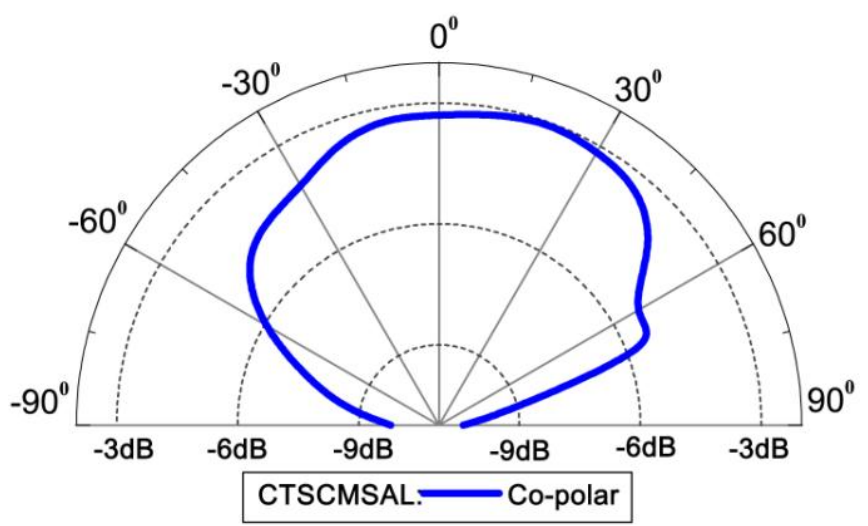

(b) 


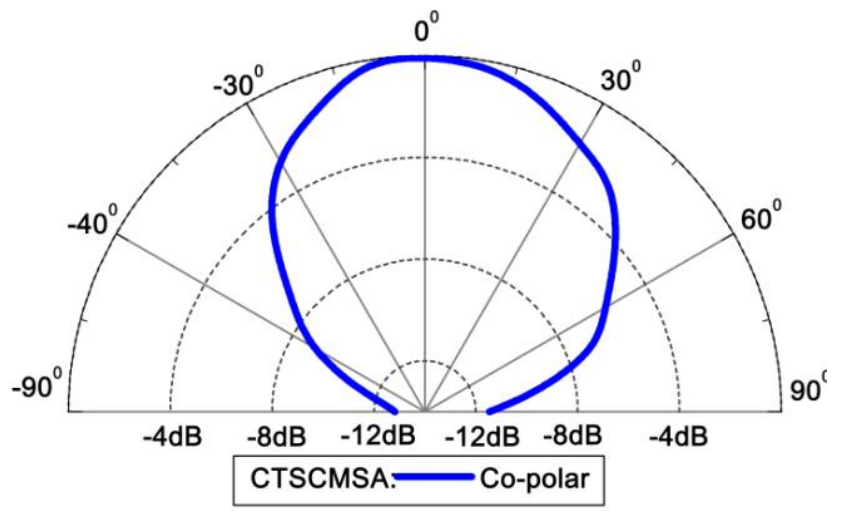

(c)

Fig-5: Typical radiation patterns of the CCMSA and CTSCMSA (a) CCMSA at $3 \mathrm{GHz}$, (b) CTSCMSA at 7.48 $\mathrm{GHz}$ and (c) CTSCMSA at $9.25 \mathrm{GHz}$.

\section{CONCLUSIONS}

This paper presents a design and development of triple-band circular microstrip antenna for $\mathrm{C}$ - and X-band applications. The proposed antenna design consists of a novel geometry of a pair of connected square slots which are etched at the center of circular patch. The proposed design is simple to construct and fabricate and uses low cost substrate material. The HFSS simulation software is used for comparison of experimental results. The obtained radiation patterns are broadsided in nature. The proposed triple-band operation is more useful for wireless communication and may find applications in uplink and downlink of $\mathrm{C}$ - and $\mathrm{X}$-band satellite communication.

\section{ACKNOWLEDGEMENTS}

The authors would like to express their sincere thanks the authorities of Department of Science and Technology (DST), Govt. of India, New Delhi, for sanctioning the Vector Network Analyzer under the FIST project to the Department of Applied Electronics, Gulbarga University, Gulbarga.

\section{REFERENCES}

[1]. Robert E. Munson, "Conformal microstrip antennas and microstrip phased arrays," IEEE, Trans. Antennas propagat., vol. AP-22, no.1, pp.74-78.

[2]. John Q. Howell, "Microstrip antennas," IEEE, Trans. Antennas propagat., pp.74-78, Jan. 1975.

[3]. Girish Kumar and K. P. Ray, Broadband microstrip antennas, London, Artech House, 2003.

[4]. Kin-Lu Wong, Compact and Broadband microstrip antennas, Wiley, New York, 2002.

[5]. J. H. Lu, C. L. Tang and K. L. Wong, "Slot-coupled small triangular microstrip antennas," Microwave Opt. Technol. Lett., Vol. 16, pp. 371-374, Dec. 20, 1998.
[6]. J. S. Kuo and K. L. Wong, "A compact microstrip antenna with meandering slots in the ground plane," Microwave Opt. Technol. Lett., Vol. 29, pp. 95-97, April 20, 2001.

[7]. R. B. Waterhouse, "Broadband stacked shorted patch," Elecrtron. Lett., vol. 35, 98-100, Jan. 21, 1999.

[8]. K. L. Wong, C. L. Tang and H. T. Chen, "A compact meandered circular microstrip antenna with a shorting pin," Microwave Opt. Technol. Lett., Vol. 15, pp. 147-149, June 20, 1997.

[9]. K.L. Lau and K.M. Luk, "Wideband folded L-slot shorted-patch antenna," Electron. Lett., vol. 41, no. 20, pp. 6019 - 6022, Sep. 29, 2005.

[10]. C. K. Anandan, P. Mohanan and K. G. Nair, "Broadband gap coupled microstrip antenna," IEEE, Trans. Antennas Propogat., vol. 38, no. 10, pp. 1581-1586, Oct. 1990.

[11]. D. M. Pozar, "A microstrip antenna aperture coupled to a microstripline," Electron. Lett., vol. 21, pp. 49-50, Jan. 1985.

[12]. S. D. Targonski, R. B. Waterhouse and D. M. Pozar, Design of wide-band aperture-stacked patch microstrip antennas," IEEE, Trans. Antennas Propogat., vol. 46, no. 9, pp. 1245-1251, Sep. 1998.

[13]. Steven (Shichang) Gao and Alistair Sambell, "Dualpolarized broad-band microstrip antennas fed by proximity coupling," IEEE, Trans. Antennas Propogat., vol. 53, no. 1, pp. 526-530, Sep. 1998.

[14]. Amit A. Deshmukh and K. P. Ray, "Broadband proximity-fed modified rectangular microstrip antennas," IEEE Antennas and Propogat. Mag., vol. 53, no. 5, pp. 41-56, Oct. 2011.

[15]. Bao F. Mang and Yuen T. Lo, "Microstrip antennas for dual-frequency operation," IEEE, Trans. Antennas Propogat., vol. AP-32, no. 9, pp. 526-530, Sep. 1984.

[16]. H. Nakano and K. Vichien, "Dual-frequency square patch antenna with rectangular notch," Electron. Lett., vol. 25, no. 16, pp. 1067-1068, Aug. 3, 1989.

[17]. R.K. Raj, M. Joseph, B. Paul and P. Mohanan, "Compact planar multiband antenna for GPS, DCS, $2.4=5.8 \mathrm{GHz}$ WLAN applications", Electron. Lett., vol. 41, no. 6, pp. 290-291, Aug. 3, 1989.

[18]. Constantine A Balanis, Antenna Theory Analysis and Design, John Wiley \& Sons, 2005.

\section{BIOGRAPHIES}

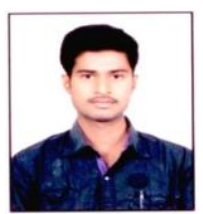

Boya Satyanarayana received his M. Sc and M. Phil degrees in Applied Electronics from the Gulbarga University, Gulbarga, Karnataka, India in 2011 and 2013 respectively. He is currently working towards his Ph.D in Applied Electronics under the guidance of Dr. S. N. Mulgi, Professor in Applied Electronics, Gulbarga University, Gulbarga. His current research interests include microwave Electronics. 


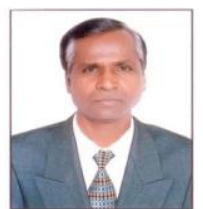

Dr. S. N. Mulgi received his M. Sc, M. Phil and $\mathrm{Ph} . \mathrm{D}$ degrees in Applied Electronics, from Gulbarga University Gulbarga in the year 1986, 1989 and 2004 respectively. He is working as a Professor in Department of P. G. Studies and Research in Applied Electronics, Gulbarga University, Gulbarga. He is an active researcher in the field of Microwave Electronics. He has published several research papers in reputed peer reviewed International and National Journals. 